\title{
Regular Weakly Generalized Closed Sets in Intuitionistic Fuzzy Topological Spaces
}

\author{
P. Rajarajeswari \\ Assistant Professor, Department of Mathematics \\ Chikkanna Government Arts College \\ Tirupur-641 602
}

\author{
L. Senthil Kumar \\ Assistant Professor, Department of Mathematics \\ SVS College of Engineering \\ Coimbatore-642 109
}

\begin{abstract}
This paper is devoted to the study of intuitionistic fuzzy topological spaces. In this paper an intuitionistic fuzzy regular weakly generalized closed set and intuitionistic fuzzy regular weakly generalized open set are introduced. Some of its properties are studied. Also we have provided some applications of intuitionistic fuzzy weakly generalized closed set namely intuitionistic fuzzy ${ }_{\mathrm{rw}} \mathrm{T}_{1 / 2}$ space and intuitionistic fuzzy $_{\mathrm{rwg}} \mathrm{T}_{1 / 2}$ space.
\end{abstract}

\section{Keywords}

Intuitionistic fuzzy topology, Intuitionistic fuzzy regular weakly generalized closed set, Intuitionistic fuzzy regular weakly generalized open set, Intuitionistic fuzzy ${ }_{\mathrm{rw}} \mathrm{T}_{1 / 2}$ space and Intuitionistic fuzzy ${ }_{\mathrm{rwg}} \mathrm{T}_{1 / 2}$ space.

\section{AMS SUBJECT CLASSIFICATION (2000): \\ 54A40, 03F55}

\section{INTRODUCTION}

Fuzzy set(FS), proposed by Zadeh [14] in 1965, as a framework to encounter uncertainity, vagueness and partial truth, represents a degree of membership for each member of the universe of discourse to a subset of it. Later on, fuzzy topology was introduced by Chang [3] in 1967.By adding the degree of non-membership to FS, Atanassov[1] proposed intuitionistic fuzzy set (IFS) in 1983 which looks more accurately to uncertainity quantification and provides the opportunity to precisely model the problem based on the existing knowledge and observations. After this, there have been several generalizations of notions of fuzzy sets and fuzzy topology. In the last few years various concepts in fuzzy were extended to intuitionistic fuzzy sets. In 1997, Coker [4] introduced the concept of intuitionistic fuzzy topological space. In this paper, we introduce one of the concepts namely regular weakly generalized closed set which were introduced initially by N.Nagaveni[8] in General Topology in 1999. After this many researchers worked on this set and developed many interesting properties and applications. We have studied some of the basic properties regarding it. We also introduced the applications of intuitionistic fuzzy regular weakly generalized closed set namely intuitionistic fuzzy ${ }_{\mathrm{rw}} \mathrm{T}_{1 / 2}$ space, intuitionistic fuzzy ${ }_{\mathrm{rwg}} \mathrm{T}_{1 / 2}$ space and obtained some characterizations and several preservation theorems of such spaces.

\section{PRELIMINARIES}

Definition 2.1: [1] Let $X$ be a non empty fixed set. An intuitionistic fuzzy set (IFS in short) $\mathrm{A}$ in $\mathrm{X}$ is an object having the form $\mathrm{A}=\left\{\left\langle\mathrm{x}, \mu_{\mathrm{A}}(\mathrm{x}), v_{\mathrm{A}}(\mathrm{x})\right\rangle / \mathrm{x} \in \mathrm{X}\right\}$ where the functions $\mu_{\mathrm{A}}(\mathrm{x}): \mathrm{X} \rightarrow[0,1]$ and $v_{\mathrm{A}}(\mathrm{x}): \mathrm{X} \rightarrow[0,1]$ denote the degree of membership (namely $\mu_{\mathrm{A}}(\mathrm{x})$ ) and the degree of non- membership (namely $v_{\mathrm{A}}(\mathrm{x})$ ) of each element $\mathrm{x} \in \mathrm{X}$ to the set A respectively and $0 \leq \mu_{\mathrm{A}}(\mathrm{x})+v_{\mathrm{A}}(\mathrm{x}) \leq 1$ for each $\mathrm{x} \in \mathrm{X}$.

Definition 2.2: [1] Let A and B be IFS's of the forms $\mathrm{A}=\left\{\left\langle\mathrm{x}, \mu_{\mathrm{A}}(\mathrm{x}), v_{\mathrm{A}}(\mathrm{x})\right\rangle / \mathrm{x} \in \mathrm{X}\right\}$ and

$\mathrm{B}=\left\{\left\langle\mathrm{x}, \mu_{\mathrm{B}}(\mathrm{x}), v_{\mathrm{B}}(\mathrm{x})\right\rangle / \mathrm{x} \in \mathrm{X}\right\}$. Then

(a) $\mathrm{A} \subseteq \mathrm{B}$ if and only if $\mu_{\mathrm{A}}(\mathrm{x}) \leq \mu_{\mathrm{B}}(\mathrm{x})$ and $\nu_{\mathrm{A}}(\mathrm{x}) \geq v_{\mathrm{B}}(\mathrm{x})$ for all $\mathrm{X} \in \mathrm{X}$

(b) $\mathrm{A}=\mathrm{B}$ if and only if $\mathrm{A} \subseteq \mathrm{B}$ and $\mathrm{B} \subseteq \mathrm{A}$

(c) $\mathrm{A}^{\mathrm{c}}=\left\{\left\langle\mathrm{x}, v_{\mathrm{A}}(\mathrm{x}), \mu_{\mathrm{A}}(\mathrm{x})\right\rangle / \mathrm{x} \in \mathrm{X}\right\}$

(d) $\mathrm{A} \cap \mathrm{B}=\left\{\left\langle\mathrm{x}, \mu_{\mathrm{A}}(\mathrm{x}) \wedge \mu_{\mathrm{B}}(\mathrm{x}), v_{\mathrm{A}}(\mathrm{x}) \vee v_{\mathrm{B}}(\mathrm{x})\right\rangle / \mathrm{x} \in \mathrm{X}\right\}$

(e) $\mathrm{A} \cup \mathrm{B}=\left\{\left\langle\mathrm{x}, \mu_{\mathrm{A}}(\mathrm{x}) \vee \mu_{\mathrm{B}}(\mathrm{x}), v_{\mathrm{A}}(\mathrm{x}) \wedge v_{\mathrm{B}}(\mathrm{x})\right\rangle / \mathrm{x} \in \mathrm{X}\right\}$

For the sake of simplicity, we shall use the notation $\mathrm{A}=\left\langle\mathrm{x}, \mu_{\mathrm{A}}, v_{\mathrm{A}}\right\rangle$ instead of $\mathrm{A}=\left\{\left\langle\mathrm{x}, \mu_{\mathrm{A}}(\mathrm{x}), v_{\mathrm{A}}(\mathrm{x})\right\rangle / \mathrm{x} \in \mathrm{X}\right\}$. Also for the sake of simplicity, we shall use the notation $\mathrm{A}=\left\langle\mathrm{x},\left(\mu_{\mathrm{A}}, \mu_{\mathrm{B}}\right),\left(v_{\mathrm{A}}, v_{\mathrm{B}}\right)\right\rangle$ instead of $\mathrm{A}=\left\langle\mathrm{x},\left(\mathrm{A} / \mu_{\mathrm{A}}, \mathrm{B} / \mu_{\mathrm{B}}\right)\right.$, $\left.\left(\mathrm{A} / v_{\mathrm{A}}, \mathrm{B} / v_{\mathrm{B}}\right)\right\rangle$.

The intuitionistic fuzzy sets $0_{\sim}=\{\langle\mathrm{x}, 0,1\rangle / \mathrm{x} \in \mathrm{X}\}$ and $1_{\sim}=\{\langle\mathrm{x}, 1,0\rangle / \mathrm{x} \in \mathrm{X}\}$ are respectively the empty set and the whole set of $X$.

Definition 2.3: [4] An intuitionistic fuzzy topology (IFT in short) on a non empty $\mathrm{X}$ is a family $\tau$ of IFS in $\mathrm{X}$ satisfying the following axioms:

(a) $0_{\sim}, 1_{\sim} \in \tau$,

(b) $\mathrm{G}_{1} \cap \mathrm{G}_{2} \in \tau$, for any $\mathrm{G}_{1}, \mathrm{G}_{2} \in \tau$,

(c) $\cup \mathrm{G}_{\mathrm{i}} \in \tau$ for any arbitrary family $\left\{\mathrm{G}_{\mathrm{i}} / \mathrm{i} \in \mathrm{J}\right\} \subseteq \tau$.

In this case the pair $(X, \tau)$ is called an intuitionistic fuzzy topological space (IFTS in short) and any IFS in $\tau$ is known as an intuitionistic fuzzy open set (IFOS for short) in X.

The complement $\mathrm{A}^{\mathrm{c}}$ of an IFOS $\mathrm{A}$ in an $\operatorname{IFTS}(\mathrm{X}, \tau)$ is called an intuitionistic fuzzy closed set (IFCS for short) in X.

Definition 2.4: [4] Let $(X, \tau)$ be an IFTS and $A=\left\langle x, \mu_{A}, v_{A}\right\rangle$ be an IFS in $X$. Then the intuitionistic fuzzy interior and an intuitionistic fuzzy closure are defined by

$\operatorname{int}(\mathrm{A})=\cup\{\mathrm{G} / \mathrm{G}$ is an IFOS in $\mathrm{X}$ and $\mathrm{G} \subseteq \mathrm{A}\}$,

$\operatorname{cl}(\mathrm{A})=\cap\{\mathrm{K} / \mathrm{K}$ is an IFCS in $\mathrm{X}$ and $\mathrm{A} \subseteq \mathrm{K}\}$.

Result 2.5: [4] Let A and B be any two intuitionistic fuzzy sets of an intuitionistic fuzzy topological space $(X, \tau)$.Then

(a) $\mathrm{A}$ is an intuitionistic fuzzy closed set in $\mathrm{X} \Leftrightarrow \operatorname{cl}(\mathrm{A})=\mathrm{A}$

(b) $\mathrm{A}$ is an intuitionistic fuzzy open set in $\mathrm{X} \Leftrightarrow \operatorname{int}(\mathrm{A})=\mathrm{A}$

(c) $\operatorname{cl}\left(\mathrm{A}^{\mathrm{c}}\right)=(\operatorname{int}(\mathrm{A}))$ 
(d) $\operatorname{int}\left(\mathrm{A}^{\mathrm{c}}\right)=(\mathrm{cl}(\mathrm{A}))^{\mathrm{C}}$

(e) $\mathrm{A} \subseteq \mathrm{B} \Rightarrow \operatorname{int}(\mathrm{A}) \subseteq \operatorname{int}(\mathrm{B})$

(f) $\mathrm{A} \subseteq \mathrm{B} \Rightarrow \operatorname{cl}(\mathrm{A}) \subseteq \operatorname{cl}(\mathrm{B})$

$(\mathrm{g}) \operatorname{cl}(\mathrm{A} \cup \mathrm{B})=\operatorname{cl}(\mathrm{A}) \cup \operatorname{cl}(\mathrm{B})$

(h) $\operatorname{int}(A \cap B)=\operatorname{int}(A) \cap \operatorname{int}(B)$

Definition 2.6: [13] Let $(X, \tau)$ be an IFTS and $A=\left\langle x, \mu_{A}, v_{A}\right.$ $>$ be an IFS in X. Then the semi closure of $A(\operatorname{scl}(A)$ in short) and semi interior of $\mathrm{A}(\operatorname{sint}(\mathrm{A})$ in short) are defined as

$\operatorname{sint}(A)=\cup\{G / G$ is an IFSOS in $X$ and $G \subseteq A\}$,

$\operatorname{scl}(\mathrm{A})=\cap\{\mathrm{K} / \mathrm{K}$ is an IFSCS in $\mathrm{X}$ and $\mathrm{A} \subseteq \mathrm{K}\}$.

Result 2.7: [11] Let A be an IFS in $(X, \tau)$, then

(i) $\operatorname{scl}(\mathrm{A})=\mathrm{A} \cup \operatorname{int}(\mathrm{cl}(\mathrm{A}))$,

(ii) $\operatorname{sint}(\mathrm{A})=\mathrm{A} \cap \operatorname{cl}(\operatorname{int}(\mathrm{A}))$.

Definition 2.8: [9] Let $(X, \tau)$ be an IFTS and $A=\left\langle x, \mu_{A}, v_{A}\right\rangle$ be an IFS in X. Then the alpha closure of $A(\alpha c l(A)$ in short) and alpha interior of $\mathrm{A}(\alpha \operatorname{int}(\mathrm{A})$ in short) are defined as

$\operatorname{\alpha int}(\mathrm{A})=\cup\{\mathrm{G} / \mathrm{G}$ is an IF $\alpha \mathrm{OS}$ in $\mathrm{X}$ and $\mathrm{G} \subseteq \mathrm{A}\}, \alpha$

$\alpha \operatorname{cl}(\mathrm{A})=\cap\{\mathrm{K} / \mathrm{K}$ is an IF $\alpha \mathrm{CS}$ in $\mathrm{X}$ and $\mathrm{A} \subseteq \mathrm{K}\}$.

Result 2.9: [9] Let A be an IFS in (X, $\tau)$, then

(i) $\alpha \operatorname{cl}(\mathrm{A})=\mathrm{A} \cup \operatorname{cl}(\operatorname{int}(\operatorname{cl}(\mathrm{A})))$,

(ii) $\operatorname{\alpha int}(\mathrm{A})=\mathrm{A} \cap \operatorname{int}(\operatorname{cl}(\operatorname{int}(\mathrm{A})))$.

Definition 2.10: An IFS $A=\left\{\left\langle x, \mu_{A}(x), v_{A}(x)\right\rangle / x \in X\right\}$ in an IFTS $(X, \tau)$ is called an

(a) intuitionistic fuzzy semi closed set (IFSCS) if $\operatorname{int}(\mathrm{cl}(\mathrm{A})) \subseteq \mathrm{A}[5]$

(b) intuitionistic fuzzy $\alpha$-closed set (IF $\alpha \mathrm{CS})$ if $\operatorname{cl}(\operatorname{int}(\operatorname{cl}(\mathrm{A}))) \subseteq \mathrm{A}[5]$

(c) intuitionistic fuzzy pre-closed set (IFPCS) if $\operatorname{cl}(\operatorname{int}(\mathrm{A})) \subseteq \mathrm{A}[5]$

(d) intuitionistic fuzzy regular closed set (IFRCS) if $\operatorname{cl}(\operatorname{int}(\mathrm{A}))=\mathrm{A}[5]$

(e) intuitionistic fuzzy generalized closed set (IFGCS) if $\mathrm{cl}(\mathrm{A}) \subseteq \mathrm{U}$ whenever $\mathrm{A} \subseteq \mathrm{U}$ and $\mathrm{U}$ is an IFOS[12]

(f) intuitionistic fuzzy generalized semi closed set (IFGSCS) if

$\operatorname{scl}(\mathrm{A}) \subseteq \mathrm{U}$ whenever $\mathrm{A} \subseteq \mathrm{U}$ and $\mathrm{U}$ is an IFOS [10]

(g) intuitionistic fuzzy $\alpha$ generalized closed set (IF $\alpha \mathrm{GCS}$ ) if

$\alpha \operatorname{cl}(\mathrm{A}) \subseteq \mathrm{U}$, whenever $\mathrm{A} \subseteq \mathrm{U}$ and $\mathrm{U}$ is an IFOS [9]

An IFS A is called intuitionistic fuzzy semi open set, intuitionistic fuzzy $\alpha$-open set, intuitionistic fuzzy pre-open set, intuitionistic fuzzy regular open set, intuitionistic fuzzy generalized open set, intuitionistic fuzzy generalized semi open set and intuitionistic fuzzy $\alpha$ generalized open set (IFSOS, IF $\alpha O S$, IFPOS, IFROS, IFGOS, IFGSOS and IF $\alpha G O S$ ) if the complement of $A^{c}$ is an IFSCS, IF $\alpha C S$, IFPCS, IFRCS, IFGCS, IFGSCS and IF $\alpha$ GCS respectively.

\section{INTUITIONISTIC FUZZY REGULAR WEAKLY GENERALIZED CLOSED SET}

In this section we introduce intuitionistic fuzzy regular weakly generalized closed set and have studied some of its properties.

Definition 3.1 An IFS A in an IFTS $(X, \tau)$ is said to be an intuitionistic fuzzy regular weakly generalized closed set $($ IFRWGCS) if $\operatorname{cl}(\operatorname{int}(\mathrm{A})) \subseteq \mathrm{U}$ whenever $\mathrm{A} \subseteq \mathrm{U}, \mathrm{U}$ is IFROS in $\mathrm{X}$.

The family of all IFRWGCSs of an IFTS $(X, \tau)$ is denoted by IFRWGCS(X).

Example 3.2: Let $X=\{a, b\}$ and let $\tau=\left\{0_{\sim}, T, 1_{\sim}\right\}$ be an IFT on $\mathrm{X}$, where $\mathrm{T}=\langle\mathrm{x},(0.3,0.3),(0.7,0.7)\rangle$. Then the IFS $\mathrm{A}=\langle\mathrm{x},(0.2,0.2),(0.8,0.7)\rangle$ is an IFRWGCS in $\mathrm{X}$.

Result 3.3: Every IFROS is an IFOS.

Proof: Let A be an IFROS in X. Therefore $\operatorname{int}(\operatorname{cl}(\mathrm{A}))=\mathrm{A}$. Which implies int(int $(\mathrm{cl}(\mathrm{A})))=\operatorname{int}(\mathrm{A})$ and hence $\operatorname{int}(\mathrm{cl}(\mathrm{A}))=$ $\operatorname{int}(\mathrm{A})$. That is $\mathrm{A}=\operatorname{int}(\mathrm{A})$. Hence $\mathrm{A}$ is an IFOS in $\mathrm{X}$.

Theorem 3.4: Every IFCS is an IFRWGCS but not conversely.

Proof: Let A be an IFCS in $(X, \tau)$. Let $\mathrm{U}$ be an intuitionistic fuzzy regular open set in $(X, \tau)$ such that $A \subseteq U$. Since $A$ is an intuitionistic fuzzy closed, $\operatorname{cl}(\mathrm{A})=\mathrm{A}$ and hence $\operatorname{cl}(\mathrm{A}) \subseteq \mathrm{U}$. But $\operatorname{cl}(\operatorname{int}(\mathrm{A})) \subseteq \operatorname{cl}(\mathrm{A}) \subseteq \mathrm{U}$. Therefore $\operatorname{cl}(\operatorname{int}(\mathrm{A})) \subseteq \mathrm{U}$. Hence $\mathrm{A}$ is an IFRWGCS in $\mathrm{X}$.

Example 3.5: Let $X=\{a, b\}$ and let $\tau=\left\{0_{\sim}, T, 1_{\sim}\right\}$ be an IFT on $\mathrm{X}$, where $\mathrm{T}=\langle\mathrm{x},(0.2,04),(07,0.6)\rangle$. Then the IFS $\mathrm{A}=\langle\mathrm{x},(0.2,0.2),(0.8,0.7)\rangle$ is an IFRWGCS in $\mathrm{X}$ but not an IFCS in $\mathrm{X}$.

Theorem 3.6: Every IF $\alpha \mathrm{CS}$ is an IFRWGCS but not conversely.

Proof: Let $\mathrm{A}$ be an IF $\alpha \mathrm{CS}$ in $\mathrm{X}$ and let $\mathrm{A} \subseteq \mathrm{U}$ and $\mathrm{U}$ is an IFROS in $(\mathrm{X}, \tau)$. By hypothesis, $\operatorname{cl}(\operatorname{int}(\operatorname{cl}(\mathrm{A}))) \subseteq \mathrm{A}$. Therefore $\operatorname{cl}(\operatorname{int}((\mathrm{A})) \subseteq \operatorname{cl}(\operatorname{int}(\operatorname{cl}(\mathrm{A}))) \subseteq \mathrm{A} \subseteq \mathrm{U}$. Therefore $\operatorname{cl}(\operatorname{int}((\mathrm{A})) \subseteq$ $\mathrm{U}$. Hence $\mathrm{A}$ is an IFRWGCS in $\mathrm{X}$.

Example 3.7: Let $\mathrm{X}=\{\mathrm{a}, \mathrm{b}\}$ and let $\tau=\left\{0_{\sim}, \mathrm{T}, 1_{\sim}\right\}$ be an IFT on $\mathrm{X}$, where $\mathrm{T}=\langle\mathrm{x},(0.4,0.3),(0.6,0.7)\rangle$. Then the IFS $\mathrm{A}=\langle\mathrm{x},(0.3,0.3),(0.7,0.6)\rangle$ is an IFRWGCS but not an IF $\alpha \mathrm{CS}$ in $\mathrm{X}$ since $\operatorname{cl}(\operatorname{int}(\mathrm{cl}(\mathrm{A})))=\langle\mathrm{x},(0.4,0.3),(0.6,0.7)\rangle \nsubseteq$ A.

Theorem 3.8: Every IFGCS is an IFRWGCS but not conversely.

Proof: Let $\mathrm{A}$ be an IFGCS in $\mathrm{X}$ and let $\mathrm{A} \subseteq \mathrm{U}$ and $\mathrm{U}$ is an IFROS in $(X, \tau)$. Since $\operatorname{cl}(A) \subseteq U, \operatorname{cl}(\operatorname{int}(A)) \subseteq \operatorname{cl}(A)$. That is $\mathrm{cl}(\operatorname{int}(\mathrm{A})) \subseteq \mathrm{cl}(\mathrm{A}) \subseteq \mathrm{U}$. Therefore $\mathrm{A}$ is an IFRWGCS in $\mathrm{X}$.

Example 3.9: Let $X=\{a, b\}$ and let $\tau=\left\{0_{\sim}, T, 1_{\sim}\right\}$ be an IFT on $\mathrm{X}$, where $\mathrm{T}=\langle\mathrm{x},(0.2,0.4),(0.8,0.6)\rangle$. Then the IFS $\mathrm{A}=\langle\mathrm{x},(0.1,0.3),(0.8,0.7)\rangle$ is an IFRWGCS but not an IFGCS in $\mathrm{X}$ since $\mathrm{A} \subseteq \mathrm{T}$ but $\operatorname{cl}(\mathrm{A})=\langle\mathrm{x},(0.8,0.6),(0.2,0.4)\rangle$ $\nsubseteq \mathrm{T}$.

Theorem 3.10: Every IFRCS is an IFRWGCS but not conversely. 
Proof: Let $\mathrm{A}$ be an IFRCS in $\mathrm{X}$ let $\mathrm{A} \subseteq \mathrm{U}$ and $\mathrm{U}$ is an IFROS in $(X, \tau)$. Since $A$ is IFRCS, $\operatorname{cl}(\operatorname{int}(A))=A \subseteq U$. This implies $\operatorname{cl}(\operatorname{int}(\mathrm{A})) \subseteq \mathrm{U}$. Hence $\mathrm{A}$ is an IFRWGCS in $\mathrm{X}$

Example 3.11: Let $X=\{a, b\}$ and let $\tau=\left\{0_{\sim}, T, 1_{\sim}\right\}$ be an IFT on $\mathrm{X}$, where $\mathrm{T}=\langle\mathrm{x},(0.3,0.5),(0.7,0.5)\rangle$. The IFS $\mathrm{A}=\langle\mathrm{x},(0.2,0.4),(0.8,0.6)\rangle$ is an IFRWGCS but not an IFRCS in $\mathrm{X}$ since $\mathrm{cl}(\operatorname{int}(\mathrm{A}))=0_{\sim} \neq \mathrm{A}$.

Theorem 3.12: Every IFPCS is an IFRWGCS but not conversely.

Proof: Let $A$ be an IFPCS in $X$ and let $A \subseteq U$ and $U$ is an IFROS in $(\mathrm{X}, \tau)$. By Definition, $\operatorname{cl}(\operatorname{int}(\mathrm{A})) \subseteq \mathrm{A}$ and $\mathrm{A} \subseteq \mathrm{U}$. Therefore $\mathrm{cl}(\operatorname{int}(\mathrm{A}) \subseteq \mathrm{U}$. Hence $\mathrm{A}$ is an IFRWGCS in $\mathrm{X}$.

Example 3.13: Let $X=\{a, b\}$ and let $\tau=\left\{0_{\sim}, T, 1_{\sim}\right\}$ be an IFT on $X$, where $T=\langle x,(0.2,0.3),(0.8,0.7)\rangle$. Then the IFS $\mathrm{A}=\langle\mathrm{x},(0.4,0.5),(0.6,0.5)\rangle$ is an IFRWGCS but not an IFPCS in $\mathrm{X}$ since $\operatorname{cl}(\operatorname{int}(\mathrm{A}))=1 \sim \nsubseteq \mathrm{A}$.

Theorem 3.14: Every IF $\alpha$ GCS is an IFRWGCS but not conversely.

Proof: Let $A$ be an IF $\alpha$ GCS in $X$ and let $A \subseteq U$ and $U$ is an IFROS in $(X, \tau)$. By Definition, $A \cup \operatorname{cl}(\operatorname{int}(\operatorname{cl}(\mathrm{A}))) \subseteq \mathrm{U}$. This implies $\operatorname{cl}(\operatorname{int}(\operatorname{cl}(\mathrm{A}))) \subseteq \mathrm{U}$ and $\operatorname{cl}(\operatorname{int}(\mathrm{A})) \subseteq \operatorname{cl}(\operatorname{int}(\operatorname{cl}(\mathrm{A}))) \subseteq \mathrm{U}$. Therefore $\mathrm{cl}(\operatorname{int}(\mathrm{A})) \subseteq \mathrm{U}$. Hence $\mathrm{A}$ is an IFRWGCS in $\mathrm{X}$.

Example 3.15: Let $X=\{a, b\}$ and let $\tau=\left\{0_{\sim}, T, 1_{\sim}\right\}$ is an IFT on $\mathrm{X}$, where $\mathrm{T}=\langle\mathrm{x},(0.5,0.5),(0.4,0.5)\rangle$. Then the IFS $\mathrm{A}=\langle\mathrm{x},(0.5,0.3),(0.5,0.7)\rangle$ is an IFRWGCS but not an $\mathrm{IF} \alpha \mathrm{GCS}$ in $\mathrm{X}$ since $\alpha \mathrm{cl}(\mathrm{A})=1_{\sim} \nsubseteq \mathrm{T}$.

Proposition 3.16: IFSCS and IFRWGCS are independent to each other which can be seen from the following example.

Example 3.17: Let $X=\{a, b\}$ and let $\tau=\left\{0_{\sim}, T, 1_{\sim}\right\}$ be an IFT on $\mathrm{X}$, where $\mathrm{T}=\langle\mathrm{x},(0.5,0.2),(0.5,0.6)\rangle$. Then the IFS $\mathrm{A}=\mathrm{T}$ is an IFSCS but not an IFRWGCS in $\mathrm{X}$ since $\mathrm{A} \subseteq \mathrm{T}$ but $\operatorname{cl}(\operatorname{int}((\mathrm{A}))=\langle\mathrm{x},(0.5,0.6),(0.5,0.2)\rangle \nsubseteq \mathrm{T}$.

Example 3.18: Let $X=\{a, b\}$ and let $\tau=\left\{0_{\sim}, T, 1_{\sim}\right\}$ be an IFT on $\mathrm{X}$, where $\mathrm{T}=\langle\mathrm{x},(0.8,0.8),(0.2,0.2)\rangle$. Then the IFS $\mathrm{A}=\langle\mathrm{x},(0.8,0.7),(0.2,0.2)\rangle$ is an IFRWGCS but not an IFSCS in $\mathrm{X}$ since int $(\mathrm{cl}(\mathrm{A})) \nsubseteq \mathrm{A}$.

Proposition 3.19: IFGSCS and IFRWGCS are independent to each other.

Example 3.20: Let $X=\{a, b\}$ and let $\tau=\left\{0_{\sim}, T, 1_{\sim}\right\}$ be an IFT on $\mathrm{X}$, where $\mathrm{T}=\langle\mathrm{x},(0.5,0.4),(0.5,0.6)\rangle$. Then the IFS $\mathrm{A}=\mathrm{T}$ is an IFGSCS but not an IFRWGCS in $\mathrm{X}$ since $\mathrm{A} \subseteq \mathrm{T}$ but $\operatorname{cl}(\operatorname{int}((\mathrm{A}))=\langle\mathrm{x},(0.5,0.6),(0.5,0.4)\rangle \nsubseteq \mathrm{T}$.

Example 3.21: Let $X=\{a, b\}$ and let $\tau=\left\{0_{\sim}, T, 1_{\sim}\right\}$ bean IFT on $X$, where $T=\langle x,(0.7,0.9),(0.3,0.1)\rangle$. Then the IFS $\mathrm{A}=\langle\mathrm{x},(0.6,0.7),(0.4,0.3)\rangle$ is an IFRWGCS but not an IFGSCS in $\mathrm{X}$ since $\operatorname{scl}(\mathrm{A}))=1 \sim$ $\nsubseteq \mathrm{T}$.

Remark 3.22: The union of any two IFRWGCS's need not be an IFRWGCS in general as seen in the following example.

Example 3.23: Let $X=\{a, b\}$ be an IFTS and let $\mathrm{T}_{1}=\langle\mathrm{x},(0.4,0.4),(0.6,0.6)\rangle$ and $\mathrm{T}_{2}=\langle\mathrm{x},(0.4,0.3),(0.6$, $0.7)\rangle$. Then $\tau=\left\{0_{\sim}, T_{1}, T_{2}, 1_{\sim}\right\}$ is an IFT on $X$ and the IFS's
$\mathrm{A}=\langle\mathrm{x},(0.4,0.2),(0.6,0.8)\rangle, \mathrm{B}=\langle\mathrm{x},(0.3,0.3)$, $(0.6,0.7)\rangle$ are IFRWGCS's but $\mathrm{A} \cup \mathrm{B}$ is not an IFRWGCS in X.

The following implications are true:

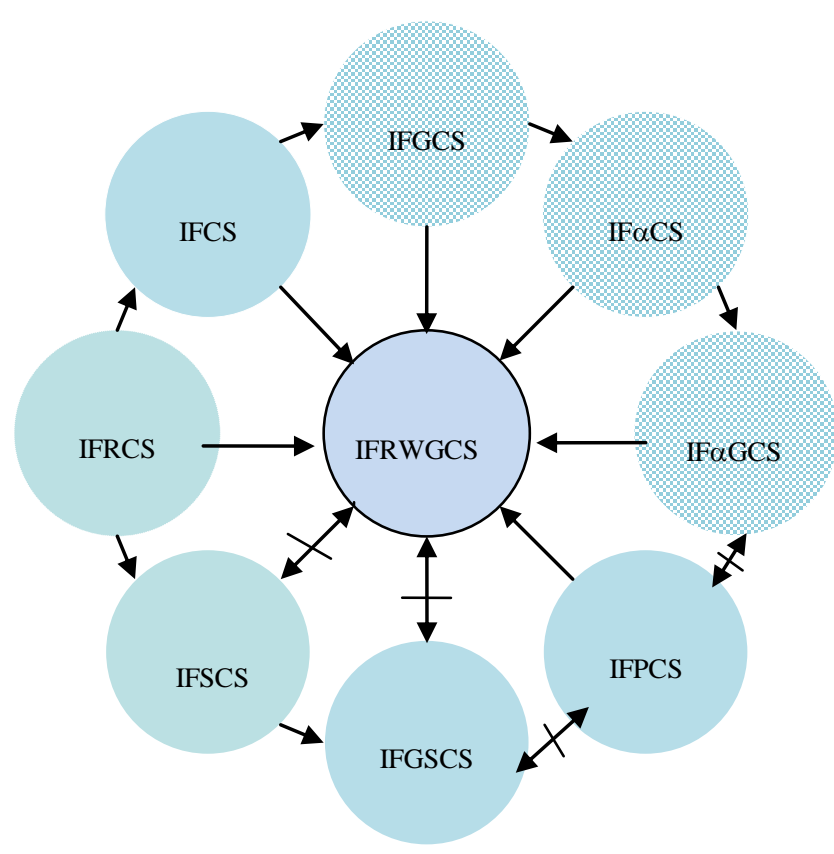

Fig.1 Relations between intuitionistic fuzzy regular weakly generalized closed set and other existing intuitionistic fuzzy closed sets.

In this diagram by "A $\rightarrow$ B" we mean A implies B but not conversely and "A 4 " means $A$ and $B$ are independent of each other.

None of them is reversible.

\section{INTUITIONISTIC FUZZY REGULAR WEAKLY GENERALIZED OPEN SETS}

In this section we introduce intuitionistic fuzzy regular weakly generalized open set and have studied some of its properties.

Definition 4.1: An IFS A is said to be an intuitionistic fuzzy regular weakly generalized open set (IFRWGOS in short) in $(\mathrm{X}, \tau)$ if the complement $\mathrm{A}^{\mathrm{c}}$ is an IFRWGCS in $\mathrm{X}$.

The family of all IFRWGOS's of an IFTS $(X, \tau)$ is denoted by IFRWGO(X).

Example 4.2: Let $\mathrm{X}=\{\mathrm{a}, \mathrm{b}\}$ and let $\tau=\left\{0_{\sim}, \mathrm{T}, 1_{\sim}\right\}$ be an IFT on $\mathrm{X}$, where $\mathrm{T}=\langle\mathrm{x},(0.3,0.3),(0.7,0.7)\rangle$. Then the IFS $\mathrm{A}=\langle\mathrm{x},(0.8,0.7),(0.2,0.2)\rangle$ is an IFRWGOS in $\mathrm{X}$.

Theorem 4.3: For any $\operatorname{IFTS}(X, \tau)$, we have the following:

(i) Every IFOS is an IFRWGOS.

(ii) Every IFPOS is an IFRWGOS.

(iii) Every IF $\alpha \mathrm{OS}$ is an IFWGOS.

(iv) Every IFGOS is an IFWGOS. But the converses are not true in general.

Proof: Straight forward. 
The converse of the above statement need not be true in general which can be seen from the following examples.

Example 4.4: Let $X=\{a, b\}$ and let $\tau=\left\{0_{\sim}, T, 1_{\sim}\right\}$ be an IFT on $X$, where $T=\langle x,(0.2,04),(07,0.6)\rangle$. Then the IFS $\mathrm{A}=\langle\mathrm{x},(0.7,0.7),(0.2,0.2)\rangle$ is an IFRWGOS in $\mathrm{X}$ but not an IFOS in $X$

Example 4.5: Let $X=\{a, b\}$ and let $\tau=\left\{0_{\sim}, T, 1_{\sim}\right\}$ is an IFT on $\mathrm{X}$, where $\mathrm{T}=\langle\mathrm{x},(0.2,0.3),(0.8,0.7)\rangle$. Then the IFS $\mathrm{A}=\langle\mathrm{x},(0.6,0.5),(0.4,0.5)\rangle$ is an IFRWGOS but not an IFPOS in $\mathrm{X}$.

Example 4.6: Let $X=\{a, b\}$ and let $\tau=\left\{0_{\sim}, T, 1_{\sim}\right\}$ is an IFT on $X$, where $T=\langle x,(0.4,0.3),(0.6,0.7)\rangle$. Then the IFS $\mathrm{A}=\langle\mathrm{x},(0.7,0.6),(0.3,0.3)\rangle$ is an IFRWGOS but not an $\mathrm{IF} \alpha \mathrm{OS}$ in $\mathrm{X}$

Example 4.7: Let $X=\{a, b\}$ and let $\tau=\left\{0_{\sim}, T, 1_{\sim}\right\}$ is an IFT on $\mathrm{X}$, where $\mathrm{T}=\langle\mathrm{x},(0.2,0.4),(0.8,0.6)\rangle$. Then the IFS $\mathrm{A}=\langle\mathrm{x},(0.8,0.7),(0.1,0.3)\rangle$ is an IFRWGOS but not an IFGOS in $\mathrm{X}$.

Theorem 4.8: An IFS A of an IFTS $(X, \tau)$ is an IFRWGOS if and only if $\mathrm{F} \subseteq \operatorname{int}(\operatorname{cl}(\mathrm{A}))$ whenever $\mathrm{F}$ is an IFCS and $\mathrm{F} \subseteq \mathrm{A}$.

Proof: Necessity: Suppose A is an IFRWGOS in X. Let F be an IFCS and $F \subseteq A$. Then $F^{c}$ is an IFOS in $X$ such that $A^{c} \subseteq$ $F^{c}$. Since $A^{c}$ is an IFRWGCS, $\operatorname{cl}\left(\operatorname{int}\left(A^{c}\right)\right) \subseteq F^{c}$. Hence $(\operatorname{int}(\operatorname{cl}(\mathrm{A})))^{\mathrm{c}} \subseteq \mathrm{F}^{\mathrm{c}}$. This implies $\mathrm{F} \subseteq \operatorname{int}(\mathrm{cl}(\mathrm{A}))$.

Sufficiency: Let $\mathrm{A}$ be an IFS of $\mathrm{X}$ and let $\mathrm{F} \subseteq \operatorname{int}(\mathrm{cl}(\mathrm{A})$ ) whenever $F$ is an IFCS and $F \subseteq A$. Then $A^{c} \subseteq F^{c}$ and $F^{c}$ is an IFOS. By hypothesis, $(\operatorname{int}(\operatorname{cl}(\mathrm{A})))^{\mathrm{c}} \subseteq \mathrm{F}^{\mathrm{c}}$. Hence $\operatorname{cl}\left(\operatorname{int}\left(\mathrm{A}^{\mathrm{c}}\right)\right) \subseteq$ $\mathrm{F}^{\mathrm{c}}$. Hence $\mathrm{A}$ is an IFRWGOS of $\mathrm{X}$.

\section{APPLICATIONS INTUITIONISTIC FUZZY REGULAR WEAKLY GENERALIZED CLOSED SETS}

In this section, we introduce intuitionistic fuzzy ${ }_{\mathrm{rw}} \mathrm{T}_{1 / 2}$ space and ${ }_{\mathrm{rwg}} \mathrm{T}_{1 / 2}$ space, which utilize intuitionistic fuzzy regular weakly generalized closed set and its characterizations are proved.

Definition 5.1: An IFTS $(X, \tau)$ is called an intuitionistic fuzzy ${ }_{\mathrm{rw}} \mathrm{T}_{1 / 2}\left(\mathrm{IF}_{\mathrm{rw}} \mathrm{T}_{1 / 2}\right.$ in short) space if every IFRWGCS in $\mathrm{X}$ is an IFCS in $\mathrm{X}$.

Definition 5.2: An IFTS $(X, \tau)$ is called an intuitionistic fuzzy ${ }_{\mathrm{rwg}} \mathrm{T}_{1 / 2} \quad\left(\mathrm{IF}_{\mathrm{rwg}} \mathrm{T}_{1 / 2}\right.$ in short) space if every IFRWGCS in $\mathrm{X}$ is an IFPCS in X.

Theorem 5.3: Every ${ }_{\mathrm{rw}} \mathrm{T}_{1 / 2}$ space is an $\mathrm{IF}_{\mathrm{rwg}} \mathrm{T}_{1 / 2}$ space. But the converse is not true in general.

Proof: Let $\mathrm{X}$ be an ${ }_{\mathrm{rw}} \mathrm{T}_{1 / 2}$ space and let $\mathrm{A}$ be an IFRWGCS in $\mathrm{X}$. By hypothesis A is an IFCS in X. Since every IFCS is an IFPCS, $A$ is an IFPCS in $X$. Hence $X$ is an $\mathrm{IF}_{r w g} T_{1 / 2}$ space.

The converses need not be true which can be seen from the following examples.

Example 5.4: Let $X=\{a, b\}, T=\langle x,(0.9,0.9),(0.1,0.1)\rangle$ and Let $\tau=\left\{0_{\sim}, \mathrm{T}, 1_{\sim}\right\}$. Then $(\mathrm{X}, \tau)$ is an $\mathrm{IF}_{\mathrm{rwg}} \mathrm{T}_{1 / 2}$ space. But it is not an ${ }_{\mathrm{rw}} \mathrm{T}_{1 / 2}$ space since the IFS $\mathrm{A}=\langle\mathrm{x},(0.2,0.2)$, $(0.8,0.7)\rangle$ is IFRWGCS but not IFCS in X.

Theorem 5.5: Let $(X, \tau)$ be an IFTS and $X$ is an ${ }_{r w} T_{1 / 2}$ space then (i) Any union of IFRWGCS is an IFRWGCS.

(ii) Any intersection of IFRWGOS is an IFRWGOS.

Proof:

(i): Let $\left\{\mathrm{A}_{\mathrm{i}}\right\}_{\mathrm{i} \in \mathrm{J}}$ is a collection of IFRWGCS in an ${ }_{\mathrm{rw}} \mathrm{T}_{1 / 2}$ space $(\mathrm{X}, \tau)$. Therefore every IFRWGCS is an IFCS. But the union of IFCS is an IFCS. Hence the Union of IFRWGCS is an IFRWGCS in X.

(ii): It can be proved by taking complement in (i).

Theorem 5.6: An IFTS $X$ is an $\mathrm{IF}_{\mathrm{rwg}} \mathrm{T}_{1 / 2} \quad$ space if and only if $\operatorname{IFRWGOS}(\mathrm{X})=\operatorname{IFPOS}(\mathrm{X})$.

Proof: Necessity: Let A be an IFRWGOS in X, then $A^{c}$ is an IFRWGCS in $\mathrm{X}$. By hypothesis $\mathrm{A}^{\mathrm{c}}$ is an IFPCS in $\mathrm{X}$. Therefore $\mathrm{A}$ is an IFPOS in $\mathrm{X}$. Hence $\operatorname{IFRWGOS}(\mathrm{X})=$ IFPOS(X).

Sufficiency: Let $A$ be an IFRWGCS in $X$. Then $A^{c}$ is an IFRWGOS in $\mathrm{X}$. By hypothesis $\mathrm{A}^{\mathrm{c}}$ is an IFPOS in $\mathrm{X}$. Therefore $A$ is an IFPCS in $X$. Hence $X$ is an IF ${ }_{r w g} T_{1 / 2}$ space.

Theorem 5.7: An IFTS $X$ is an IF $\mathrm{IF}_{1 / 2}$ space if and only if $\operatorname{IFRWGOS}(\mathrm{X})=\operatorname{IFOS}(\mathrm{X})$.

Proof: Necessity: Let $A$ be an IFRWGOS in $X$, then $A^{c}$ is an IFRWGCS in X. By hypothesis $A^{c}$ is an IFCS in X. Therefore $\mathrm{A}$ is an IFOS in $\mathrm{X}$. Hence $\operatorname{IFRWGOS}(\mathrm{X})=\operatorname{IFOS}(\mathrm{X})$.

Sufficiency: Let $A$ be an IFRWGCS in $X$. Then $A^{c}$ is an IFRWGOS in $\mathrm{X}$. By hypothesis $\mathrm{A}^{\mathrm{c}}$ is an IFPOS in $\mathrm{X}$. Therefore $A$ is an IFPCS in $X$. Hence $X$ is an ${ }_{r w} T_{1 / 2}$ space.

\section{CONCLUSION}

In this paper we have introduced intuitionistic fuzzy regular weakly generalized closed set and studied some of its basic properties. Also we have studied the relationship between intuitionistic fuzzy regular weakly generalized closed and some of the intuitionistic fuzzy sets already exist.

\section{REFERENCES}

[1] K.T.Atanassov,Intuitionistic fuzzy sets, Fuzzy Sets and Systems, 20 (1986), 87-96.

[2] P.Bhattacharyya and B.K.Lahiri, Semi generalized closed sets in topology, Indian J. Math, 29(1987), 375382 .

[3] C.L.Chang, Fuzzy topological spaces, J.Math.Anal.Appl, 24(1968), 182-190.

[4] D.Coker, An introduction to intuitionistic fuzzy topological spaces, Fuzzy sets and systems, 88(1997), 81-89.

[5] H.Gurcay, A.Haydar and D.Coker, On fuzzy continuity in intuitionistic fuzzy topological spaces, jour. of fuzzy math, 5(1997), 365-378.

[6] I.M.Hanafy,Intuitionistic fuzzy $\gamma$ continuity, Canad. Math Bull. XX (2009), 1-11.

[7] C.Mukundhan and N.Nagaveni, A Weaker form of a Generalized closed set, Int.J.Contemp.Math.Sciences, 20(2011), 949-961.

[8] N.Nagaveni, Studies on generalized on homeomorphisms in topological spaces, Ph.D Thesis, Bharathiar University, Coimbatore 1999. 
[9] Sakthivel, K., 2010, "Intuitionistic Fuzzy Alpha Generalized Continuous Mappings and Intuitionistic Alpha Generalized Irresolute Mappings," Applied Mathematical Sciences., Vol. 4, no. 37., pp. 1831 1842.

[10] Santhi, R. and Sakthivel, K., Intuitionistic fuzzy generalized semicontinuous mappings, Advances in Theoretical and Applied Mathematics, 5 (2009), 73-82.

[11] T.Shyla Isac Mary and P.Thangavelu, On Regular PreSemiclosed Sets in Topological Spaces, KBM Journal of
Mathematical Sciences \& Computer Applications 1(2010), 9- 17.

[12] S.S.Thakur and Rekha Chaturvedi, R.G-closed sets in intuitionistic fuzzy topological spaces ,Universitatea Din Bacau Studii Si Cercertar Stiintifice, 6(2006), 257-272.

[13] Young Bae Jun and Seok-Zun Song, Intuitionistic fuzzy semi-pre open sets and Intuitionistic semi-pre continuous mappings, Jour.of Appl.Math and Computing, 19(2005), 464-474.

[14] L.A.Zadeh, Fuzzy sets, Information control, 8 (1965) 338-353. 